\title{
Lipid-lowering therapies and achievement of LDL-cholesterol targets
}

\author{
Manfredi Rizzo ${ }^{1,2}$, Maciej Banach³, Giuseppe Montalto², Dimitri P. Mikhailidis
}

1Department of Internal Medicine and Medical Specialties, University of Palermo, Italy
2Euro-Mediterranean Institute of Science and Technology, Italy
${ }^{3}$ Department of Hypertension, Medical University of Lodz, Poland
${ }^{4}$ Department of Clinical Biochemistry (Vascular Disease Prevention Clinics), Royal Free
Campus, University College London Medical School, University College London (UCL),
Pond Street, London, UK

Submittted: 26 July 2012

Accepted: 15 August 2012

Arch Med Sci 2012; 8, 4: 598-600

DOI: 10.5114/aoms.2012.30281

Copyright (c) 2012 Termedia \& Banach

In the present issue of Archives of Medical Science, Mark et al. [1] report the results of a survey conducted last year in Hungary. This consisted of 1,626 adult patients with high cardiovascular (CV) risk, due to unstable angina (23\%), peripheral artery disease (17\%), previous myocardial infarction (34\%), stroke (30\%) or transient ischemic attack (17\%). The main aim of the study was to assess the achievement of low density lipoprotein cholesterol (LDL-C) target levels, and to compare it with previous data from surveys performed by the same authors. The LDL-C target value in the present study was $2.6 \mathrm{mmol} / \mathrm{l}(100 \mathrm{mg} / \mathrm{dl})$, in line with the recommendation of the Hungarian Cardiovascular Consensus Conference (2010) [2]; using this LDL-C target, the authors reported a $43.3 \%$ achievement rate. Furthermore, they noticed that the goal achievement rate was higher in patients followed by specialists $(n=1,152)$ vs. those followed by general practitioners ( $n=474)$ ( $45 \%$ vs. $40 \%$, respectively), but this difference did not reach significance [1].

The overall achievement rate was poor despite the high CV risk; this is a common problem in Europe and especially in Central and Eastern European countries [3]. As recently discussed [4], although the quality of lipidlowering treatments has improved, in many European countries therapeutic inertia and a lack of sufficient knowledge regarding the best management of patients with lipid disorders remains an important problem $[4,5]$. In addition, there is insufficient collaboration between specialists and primary care physicians [3-5]. We discuss potential problems of adherence to therapy in 3 different categories: patient-, prescriber- and drug-related factors.

Regarding patient-related factors, it is important to highlight the potential role of side effects and polypharmacy; indeed, patients at high CV risk usually need several drugs (e.g. anti-hypertensive, anti-diabetic and antiplatelet drugs). This was also true for the patients included in the Mark et al. study [1], where $46 \%$ had diabetes and $88 \%$ hypertension. Other patient-related factors include patient participation and understanding why the treatment is needed (awareness). This is linked to attendance and optimal frequency of follow-up visits [4-6].

Prescriber-related factors include the knowledge of LDL-C guideline targets, which have become more difficult to achieve over the years: this is a universal phenomenon that persisted during the decade 2000 to 2010

\author{
Corresponding author: \\ Maciej Banach MD, PhD, \\ FAHA, FNLA, FESC, FASA, \\ FRSPH \\ Department of Hypertension \\ WAM University Hospital \\ in Lodz \\ Medical University of Lodz \\ Zeromskiego 113 \\ 90-549 Lodz, Poland \\ Phone: +48 426393771 \\ Fax: +48 426393782 \\ E-mail: \\ maciejbanach@aol.co.uk
}


[7]. There have been prospective attempts to improve this situation, but mainly focused on the time after the acute event; in contrast, there have only been a few attempts to improve adherence in secondary cardiovascular disease (CVD) prevention drugs away from the acute event, taking into account "real word data" [8]. In the Greek atorvastatin on coronary heart disease evaluation (GREACE) [9], patients with established coronary artery disease (CAD) were randomised either to "structured care" (atorvastatin titrated from 10 to $80 \mathrm{mg} /$ day in order to achieve an LDL-C target of $2.6 \mathrm{mmol} / \mathrm{l}$, $100 \mathrm{mg} / \mathrm{dl} ; n=800$ ) or to "usual" medical care $(n=800)$. Patients were followed for a mean of 3 years and there was an effort to keep the "structured care" group of patients on statins; this resulted in the achievement of the LDL-C goal in $95 \%$ of patients. Other prescriber-related factors include the training and the cost limitations (generic drugs, government funding, insurance etc.) [9].

Another crucial issue is the role of specialist vs. non-specialist in the treatment of lipid disorders. It has recently been highlighted that therapeutic inertia [4], lack of (or insufficient) knowledge and mistakes by physicians (especially general practitioners) are reasons why they do not use high doses of statins and very often decrease the doses of statins in patients who receive them after hospitalization or consultation with specialists. This is also true for the study of Mark et al. [1], where achievement rate was higher in patients followed by specialists than general practitioners. In addition, in this latter study [1], the authors stratified their high risk patients according to the new dyslipidaemia guidelines of the European Society of Cardiology (ESC)/European Atherosclerosis Society (EAS) [10]; as a result of this, $83 \%$ of their patients belonged to the very-high risk category with an LDL-C target value of $1.80 \mathrm{mmol} / \mathrm{l}$ $70 \mathrm{mg} / \mathrm{dl}$ ). Only $11 \%$ of the very-high risk patients ollowed by general practitioners achieved this stricter LDL-C target [1]. This again supports the concept of therapeutic inertia, as well as the need of specialized professionals (physician and nurse services).

Further, drug-related factors may potentially interfere with adherence to therapy. Combination therapy is often necessary in subjects with high or very-high CV risk (usually with atherogenic dyslipidemia) but it may not be used as a result of a number of potential issues, including lack of knowledge, high cost of therapy, lack of evidence and decreased adherence due to polypharmacy [11]. Combination formulations may result in greater adherence, and there is already experience with successful results with combination therapy for lipid disorders [12, 13]. It should also be highlighted that lipid-lowering treatments have additional benefits, such as on kidney function, non-alcoholic fatty liver disease
(NAFLD) and thrombosis [14]. This may be counteracted by statin-related increased new onset of diabetes [15], but it is important that the CV and mortality benefits of statin therapy significantly exceed the diabetes hazard, even in patients at high risk of developing diabetes [16-18].

Finally, there is currently a strong debate whether we should treat patients on the basis of their plasma lipid levels or on the basis of their risk [19]. Most international guidelines as well as several expert panels have confirmed that LDL-C represents the primary or even the only target of therapy $[5,10,13]$. Yet, increasing evidence suggests abandoning the paradigm of treating dyslipidemic patients to LDL-C targets only and moving away to a more tailored treatment approach. In this context, atherogenic dyslipidemia and its associated risk would become a target of tailored therapy. Indeed, increasing evidence suggests that the "quality" of plasma lipids (e.g. small, dense LDL and dysfunctional high density lipoprotein $[13,20,21])$. In conclusion, we should not treat the cholesterol, but the risk!

\section{Acknowledgments}

Declaration of interest - Manfredi Rizzo has given talks and participated in conferences sponsored by Bracco, Chiesi Farmaceutici, Novo-Nordisk and Servier. Maciej Banach has given talks, attended conferences and participated in trials sponsored by MSD, Abbott, Servier, Merck. Dimitri P. Mikhailidis has given talks, attended conferences and participated in trials and advisory boards sponsored by MSD, Genzyme and Abbott.

\section{References}

1. Mark L, Paragh G, Karadi I, Reiber I, Pados G, Kiss Z. How can we further improve the LDL-cholesterol target level achievement rate based on the Hungarian MULTI GAP 2011 study results and considering the new European dyslipidaemia guidelines? Arch Med Sci 2012; 8: 608-13.

2. The IV. Hungarian Cardiovascular Consensus Conference. Metabolizmus 2010; 8 Suppl A: 2-96.

3. Kozela M, Szafraniec K, Broda G, et al.; POLKARD Study Group. Detection and treatment of hypercholesterolemia in primary health care. Results of the POLKARD program of the Ministry of Health of the Republic of Poland. Pol Arch Med Wewn 2012; 122: 154-61.

4. Banach M, Davidson M, Toth PP. Polish Lipid Association: a strong response to the problem of lipid disorders in Poland and Central and Eastern Europe. J Clin Lipidol 2012; 6: 105-7.

5. Barylski M, Małyszko J, Rysz J, Myśliwiec M, Banach M. Lipids, blood pressure, kidney: what was new in 2011? Arch Med Sci 2011; 7: 1055-66.

6. Bielecka-Dabrowa A, Aronow WS, Rysz J, Banach M. The rise and fall of hypertension: lessons learned from Eastern Europe. Curr Cardiovasc Risk Rep 2011; 5: 174-9

7. Klingman D, Williams SA, Benner JS, Smith TW, Ahn J, O'Donnell JC. Gauging the treatment gap in dyslipidemia: 
findings from the 1999-2000 National Health and Nutrition Examination Survey. Am Heart J 2005; 150: 595-601.

8. Athyros VG, Gossios TD, Katsiki N, Karagiannis A, Mikhailidis DP. The clinical benefit of implementing guidelines in cardiovascular disease prevention in real world settings. Arch Med Sci 2012; 8: 6-10.

9. Athyros VG, Papageorgiou AA, Mercouris BR, et al. Treatment with atorvastatin to the National Cholesterol Educational Program goal versus 'usual' care in secondary coronary heart disease prevention. The GREek Atorvastatin and Coronary-heart-disease Evaluation (GREACE) study. Curr Med Res Opin 2002; 18: 220-8.

10. Reiner Z, Catapano AL, De Backer G, et al. The Task Force for the management of dyslipidaemias of the European Society of Cardiology (ESC) and the European Atherosclerosis Society (EAS). ESC/EAS Guidelines for the management of dyslipidaemias. Eur Heart J 2011; 32: 1769-818.

11. Banach M, Mikhailidis DP, Kjeldsen SE, Rysz J. Time for new indications for statins? Med Sci Monit 2009; 15: MS1-5.

12. Michos ED, Sibley CT, Baer JT, Blaha MJ, Blumenthal RS. Niacin and statin combination therapy for atherosclerosis regression and prevention of cardiovascular disease events: reconciling the AIM-HIGH (Atherothrombosis Intervention in Metabolic Syndrome With Low HDL/High Triglycerides: Impact on Global Health Outcomes) trial with previous surrogate endpoint trials. J Am Coll Cardiol 2012; 59: 2058-64.

13. Otocka-Kmiecik A, Mikhailidis DP, Nicholls SJ, Davidson M, Rysz J, Banach M. Dysfunctional HDL: a novel important diagnostic and therapeutic target in cardiovascular disease? Prog Lipid Res 2012; 51: 314-24.

14. Athyros VG, Kakafika Al, Tziomalos K, Karagiannis A, Mikhailidis DP. Pleiotropic effects of statins: clinical evidence. Curr Pharm Des 2009; 15: 479-89.

15. Rizzo M, Spinas GA, Rini GB, Berneis K. Is diabetes the cost to pay for a greater cardiovascular prevention? Int J Cardiol 2010; 144: 309-10.

16. Katsiki N, Banach M. Statins and the risk of diabetes: the debate. Arch Intern Med 2012; 172: 895-6.

17. Ridker PM, Pradhan A, MacFadyen JG, Libby P, Glynn RJ. Cardiovascular benefits and diabetes risks of statin therapy in primary prevention: an analysis from the JUPITER trial. Lancet 2012; 380: 565-71.

18. Katsiki N, Banach M. Statin use and risk of diabetes mellitus in postmenopausal women. Clin Lipidol 2012; 7 : 267-70.

19. Hayward RA, Krumholz HM. Three reasons to abandon low-density lipoprotein targets: an open letter to the Adult Treatment Panel IV of the National Institutes of Health. Circ Cardiovasc Qual Outcomes 2012; 5: 2-5.

20. Rizzo M, Mikhailidis DP. There is more to predicting vascular disease than just established risk factors. Curr Pharm Des 2011; 17: 3608-10.

21. Mikhailidis DP, Elisaf MS, Rizzo M, et al. "European Panel on Low Density Lipoprotein (LDL) Subclasses": a statement on the pathophysiology, atherogenicity and clinical significance of LDL subclasses. Curr Vasc Pharmacol 2011; 9: $533-71$ 